\title{
Analisis Strategi Promosi pada UMKM Social Enterprise (Studi Kasus Pascorner Cafe and Gallery)
}

\author{
Annisa Nurul Fildzah \\ Prodi S1 Ilmu Komunikasi Universitas Telkom \\ ansnf96@gmail.com \\ Ira Dwi Mayangsari \\ Prodi S1 Ilmu Komunikasi Universitas Telkom \\ iradwio6o3@yahoo.com
}

\begin{abstract}
Abstrak
Pascorner Cafe And Gallery merupakan cafe dengan 90\% karyawannya adalah mantan narapidana. Dalam konteks ini, masyarakat masih sering memandang sebelah mata kepada Pascorner, strategi promosi yang tepat akan menghilangkan persepsi tersebut. Tujuan penelitian ini adalah untuk menganalisis dan mengevaluasi strategi promosi yang telah diterapkan, serta merumuskan alternatif strategi promosi untuk digunakan oleh Pascorner. Metode yang dipakai pada penelitian ini adalah jenis penelitian kualitati,dengan pendekatan studi kasus. Hasil penelitian menunjukan bahwa Pascorner dalam menjalankan kegiatan strategi promosi menggunakan tools advertising, sales promotion serta public relation. Selanjutnya, alternatif strategi promosi yang disusun menggunakan IMC Model Dwi Sapta karena dapat menggambarkan secara jelas dan detil bagaimana lingkungan eksternal, internal serta sudut pandang Pascorner kacamata konsumen.
\end{abstract}

Kata Kunci: UMKM, Social Enterprise, Promotion Mix, IMC Model Dwi Sapta

\begin{abstract}
The culinary business of Micro, Small, Medium Enterprise (MSME) is nowadays the most promising business industry, especially in Bandung, West Java. The beginners believe that culinary business is easy to run. One of the beginners is Pascorner Cafe And Gallery. This special cafe is run by almost 90\% ex-prisoner. However people still always underestimate its existence, but the founder believes that with the right promotion strategy, will erase those negative perception. The main goal of this study is to analyze and evaluate the promotion strategy applied by Pascorner and moreover to form an alternative way to support its former promotion strategy. The researcher applied a qualitative method combined with a case study approach. The research showed that Pascorner has been using tools are advertising, sales promotion, and public relation. Alternative promotion strategy formed by the researcher is using Dwi Sapta IMC Model, it could describe how the external and internal environment is and how the people opinion is, clearly and in detail
\end{abstract}

Keywords: MSME, Social Enterprise, Promotion Mix, IMC Model Dwi Sapta 


\section{PENDAHULUAN}

Usaha Mikro Kecil Menengah atau UMKM di Indonesia menunjukan eksistensinya dari beberapa tahun kebelakang. menurut data dari Bank Indonesia pada 2014, UMKM memiliki peran penting bagi perekonomian di Indonesia karena UMKM mempunyai tingkat penyerapan tenaga kerja sekitar 97\% dari seluruh tenaga kerja nasional dan mempunyai kontribusi terhadap produk domestik sekitar 57\%. Pesatnya pertumbuhan pada bisnis kuliner diakibatkan para pemula melihat adanya peluang untuk membuka bisnis yang menjanjikan dan terhitung mudah untuk dijalankan. Salah satu cara agar tetap mampu bersaing dengan kompetitor adalah dengan melakukan promosi. Dengan menjalankan promosi yang sesuai dan efektif, usaha yang dijalankan akan lebih dikenal kepada masyarakat luas, mendatangkan konsumen dan mempertahankan konsumen loyal.

Lokasi usaha kuliner juga mempengaruhi pengetahuan konsumen terkait awareness yang dibangun oleh khalayak. Maka dari itu, UMKM khususnya usaha mikro, promosi yang aktif. Cafe seperti Pascorner Cafe and Gallery harus memiliki promosi yang unik dan menarik karena promosi berguna agar usaha kuliner tetap bisa bertahan. Terlebih lagi lokasi usaha Pascorner ada di kawasan pertokoan, tepatnya di daerah Lapas Banceuy Bandung.

Pascorner Cafe and Gallery merupakan salah satu cafe resto yang menyuguhkan sebuah keunikan yang beda daripada cafe resto pada umumnya. Dengan konsep atau ide yang sangat unik, mereka menjajakan tempat yang nyaman, makanan minuman yang bervariasi, serta tempat santai dengan ditemani secangkir kopi. Bukan hanya itu saja, 90\% karyawannya adalah para mantan narapidana yang ingin mengubah hidupnya ke arah yang lebih postif dan bermanfaat.

Pascorner Cafe and Gallery merupakan salah satu usaha yang bersifat social enterprise. Social enterprise adalah sebuah organisasi yang secara langsung terlibat dalam penjualan barang dan jasa di pasar. PT. AVA sebagai penyokong dana dan yang membina, dari mitra koperasi Lapas seluruh Indonesia, membantu dalam hal finansial pada saat pembuatan Pascorner Cafe and Gallery. Pascorner hadir untuk melawan stereotype yang berkembang di masyarakat. Di Pascorner Cafe and Gallery, para mantan narapidana menuangkan kreativitasnya.

Dalam konteks UMKM, social enterprise, yaitu Pascorner Cafe and Gallery, yang berlokasi di kawasan Lapas Banceuy, serta 90\% karyawannya adalah mantan narapidana, masyarakat masih sering memandang sebelah mata kepada Pascorner. Untuk itu, penyusunan strategi promosi yang tepat, digunakan untuk mengubah persepsi tersebut dari masyarakat dengan menerapkan tools yang ada di bauran promosi (promotion mix). Penggunaan media daring dan konvensional untuk mempromosikan Pascorner, akan menjadi lebih efisien apabila strategi promosi yang dipakai tepat sasaran.

Berdasarkan permasalahan yang ada, untuk memberikan alternatif strategi promosi yang cocok dengan karakteristik Pascorner, peneliti akan menggunakan IMC model Dwi Sapta. Masalah yang akan diidentifikasi oleh penulis dalam penelitian ini adalah bagaimana strategi promosi 
yang dilakukan Pascorner Cafe and Gallery pada media konvensional dan media daring dan bagaimana alternatif strategi promosi yang sesuai untuk Pascorner Cafe and Gallery?.

\section{METODE}

Dalam penelitian ini, penulis menggunakan paradigma konstruktivisme. Konstruktivisme menerangkan bahwa semesta secara epistomologi merupakan hasil konstruksi sosial. Paradigma konstruktivis dipengarui oleh perspektif interaksi simbolis dan perspektif strukturan fungsional.

Peneliti berupaya memaknai ucapan dan penjelasan subjek penelitian atas objek yang diteliti. Konstruktivisme memiliki asumsi bahwa manusia akan terlibat dengan dunia dan lingkungan mereka dalam memaknai sesuatu. Jadi dengan menggunakan paradigma ini, peneliti ingin membangun sebuah makna yang diperoleh dari wawancara informan utama, pendukung dan triangulasi sumber serta berlandaskan elemen strategi promosi yang sesuai dengan konsep bauran promosi. Selanjutnya merancang alternatif strategi promosi yang tepat dengan konsep IMC Model.

Penelitian kali ini merupakan jenis penelitian dengan metode kualitatif, dengan pendekatan studi kasus. Penelitian kualitatif cara kerjanya adalah data yang dikumpulkan lebih menggambil bentuk kata-kata atau gambar daripada angkaangka. Dalam penelitian kualitatif, metode yang digunakan biasanya pengamatan, wawancara dan penelaahan dokumen (Moleong, 2007: 9). Peneliti menggunakan pendekatan studi kasus yang mana menurut Yin (2008: 18) studi kasus merupakan suatu inkuiri empiris yang menyelidiki fenomena di dalam kontes kehidupan nyata, bilamana batas-batas antara fenomena dan konteks tidak tampak dengan tegas dan memanfaatkan multisumber terkait data atau bukti yang dibutuhkan.

Peneliti melakukan penelitian dengan cara wawancara, dokumentasi serta observasi ke tempat penelitian, kasus yang peneliti angkat adalah bagaimana strategi promosi yang dilakukan oleh Pascorner Cafe and Gallery, serta menganalisis apabila terjadi kekurangan dalam promosinya, sehingga peneliti menyusun alternatif strategi promosi untuk Pascorner Cafe and Gallery.

\section{HASIL DAN PEMBAHASAN}

\section{Bauran Promosi (Promotion Mix)}

Menurut Kotler \& Armstrong (2008: 116), bauran promosi (promotion mix) yang juga disebut bauran komunikasi pemasaran (marketing communication mix) adalah cara-cara untuk mempromosikan suatu pesan dari perusahaan yang didalamnya terdapat tools berupa iklan, penjualan personal, promosi penjualan, hubungan masyarakat dan pemasaran langsung.

Pascorner Cafe and Gallery telah menggunakan strategi ini,tapi dari kelima tools, Pascorner hanya menggunakan tiga tools yakni, iklan, promosi penjualan serta public relations. Berikut pembahasan tentang bauran promosi di Pascorner Cafe and Gallery

\section{a. Advertising}

Menurut Kotler \& Armstrong (2008), mengartikan periklanan (advertising) sebagai semua bentuk presentasi non-pribadi dari promosi ide, 
barang, atau jasa yang dibayar oleh sponsor tertentu. Pascorner Cafe and Gallery telah menggunakan berbagai cara untuk mengkomunikasikan pesannya, agar khalayak dan target audiens mengetahui tentang Pascorner.

\section{1) Media Konvensional}

$\begin{array}{ccc}\text { Cara mengkomunikasikan } & \text { pesan } \\ \text { dengan } & \text { menggunakan } & \text { media }\end{array}$
konvensional telah digunakan oleh Pascorner dengan cara beriklan melalui pembagian brosur pada saat daerah Soekarno Hatta macet. Brosur biasanya berisikan menu-menu pilihan dan berbagai macam tawaran yang diberikan oleh Pascorner, Standing banner dipasang pada pintu masuk cafe, dimana standing banner menyampaikan promosi pilihan tergantung dengan program promosi yang dipakai, lalu pemasangan spanduk, serta penempatan placemat menu pada meja di Pascorner. Ini, dilakukan agar konsumen lebih mudah dan langsung mendapatkan terpaan promosi yang dibangun oleh Pascorner.

\section{2) Media Daring}

Media daring yang digunakan oleh Pascorner adalah melalui media sosial Instgram pada akun @Pascorner17. Akunnya digunakan untuk membagikan promo, aktivitas yang sedang berlangsung atau akan berlangsung di Pascorner hingga membagikan poster elektronik tentang event yang berlangsung di Pascorner. Hasil informasi yang didapatkan, menurut informan pendukung yaitu konsumen, cara ini yang paling sering dilihat oleh konsumen atau target audiens dibandingkan iklan dari media konvensional.

\section{b. Sales Promotion}

Menurut Kotler dan Amstrong (2008: 117), sales promotion dijelaskan sebagai insentif jangka pendek untuk mendorong pembelian atau penjualan produk atau jasa. Cara ini digunakan untuk meningkatkan jumlah barang yang dibeli pelanggan karena konsumen cenderung menyukai potongan harga. Pascorner memiliki tawaran Membercard untuk setiap konsumen yang melakukan pembelian diatas Rp. 300.000, dan pembelian selanjutnya akan dikenakan diskon dengan menunjukan kartu keanggotaannya saja. Maka, secara langsung, Pascorner mampu men-engage konsumen agar lebih loyal.

\section{c. Public Relations}

Public relations merupakan salah catu cara yang efektif untuk membuat produk atau merek kita dibicarakan. Menurut Kotler dan Armstrong (2008: 168), hubungan masyarakat (public relations) berarti usaha perusahaan dalam membangun hubungan yang baik dengan masyarakat untuk membangun citra perusahaan yang positif dan mendapatkan publisitas yang diinginkan. Pascorner menggunakan cara ini sebagai andalan promosi secara tidak langsung. Event merupakan salah satu cabang turunan dari public relation. Dengan Pascorner mengadakan event komunitas atau event musik yang ditiap minggunya berbeda genre, serta disetiap pembukaan acara, pihak Pascorner akan menjelaskan sejarah Pascorner dan siapa Pascorner. Hal ini merupakan salah satu strategi dari mereka 
agar menyasar ke semua segmen dan menjadikan Pascorner word of mouth. Menurut informan yang merupakan ahli di bidang marketing, cara ini merupakan cara yang efektif untuk menggaet semua segmen dan menyita perhatian masyarakat hingga target audiens. Menurut informan ahli, yang perlu diperhatikan pada saat penyusunan strategi promosi itu adalah segmentasi. Hal ini sudah dilakukan oleh Pascorner karena Pascorner sudah memiliki segmentasi yang jelas dan menyasar ke semua segmen.

\section{Pemetaan Strategi Promosi}

\section{a. Discovery Circle}

\section{1) Market Review}

Menurut Watono \& Watono (2011: 82), market review merupakan analisis rerhadap kondisi pasar terhadap berbagai aspek tren dan perubahan. Dalam analisis pasar pada Pascorner, peneliti mencari informasi dari berbagai sumber, yakni informan utamaPascorner, informan pendukungpara konsumen dan informasi ahli) . Analisis dilakukan dengan mencari informasi terkait kelemahan dan kekuatan yang dimiliki Pascorner dari pandangan konsumen, lalu mengetahui penggunaan teknologi yang digunakan oleh Pascorner dengan mencari informasi kepada pihak Pascorner, serta mengulas tren ekonomi industri cafe, di lini UMKM bersifat social enterprise kepada informan ahli di bidangnya.

Berdasarkan hasil wawancara dan observasi, Pascorner Cafe and Gallery memiliki kekuatan, yakni kemampuannya mengadakan event berbeda genre di setiap minggunya untuk menggaet semua segmen, memiliki konsep unik tentang perubahan dari 90\% karyawannya yang merupakan mantan narapidana, dan lokasi strategis dekat Lapas Banceuy Bandung. Namun, Pascorner mempunyai kelemahan, yakni tempat relatif kecil untuk mengadakan event-event musik. Untuk menemukan lokasi cafe harus masuk ke dalam komplek dan jarang orang mencari cafe di daerah tersebut.

Penggunaan Teknologi yang Berhubungan dengan Pascorner Cafe and Gallery adalah reservasi melalui telepon serta memiliki media sosial; Instagram@Pascorner17

Menurut informan ahli ekonomi dan kewirausahaan, kecenderungan ekonomi di industri cafe itu berkembang, tapi Bandung sudah berada di saturation market, yang artinya sudah ada di pasar jenuh, karena di Bandung sudah banyak menjamur bisnis kuliner.

\section{2) Competitor Review}

Analisis kompetitor, menurut Watono \& Watono (2011), merupakan langkah untuk memahami kondisi, strategi dan gerak langkah pesaing yang akan kita hadapi dalam persaingan pasar. Analisis pesaing ini juga bisa dilakukan dengan cara pendekatan lewat kacamata konsumen atau menurut persepsi konsumen. Dalam analisis kompetitor yang dibangun oleh persepsi konsumen, peneliti mencari informasi untuk mendapatkan unsur-unsur yang dibutuhkan pada saat penelitian. Mengetahui kekuatan dan daya saing kompetitor, serta mengetahui persepsi konsumen, peneliti dapat membandingkan Pascorner Cafe and Gallery dengan kompetitor yang telah peneliti pilih. Kompetitor dipilih 
berdasarkan jarak terdekat dengan lini usaha yang sama, yaitu cafe.

Gambar 2 Pascorner dan Kompetitor dalam Maps

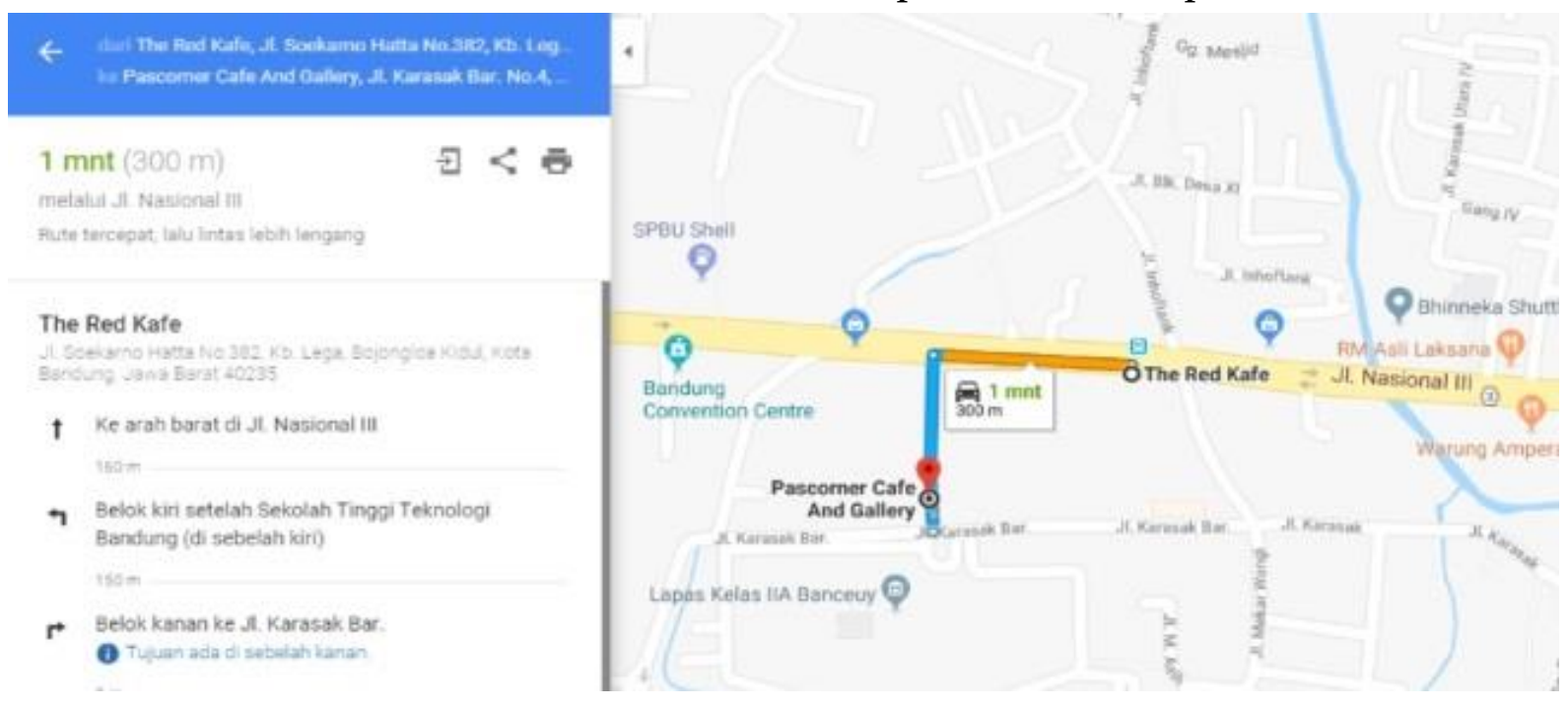

Dilakukan wawancara kepada 3 informan pendukung, yaitu konsumen, terkait perbandingan Pascorner Cafe and Gallery dengan kompetitornya. Kompetitor terdekat, yaitu sejauh $300 \mathrm{~m}$ dengan Pascorner adalah The Red Kafe di Jalan Soekarno Hatta No. 382 yang merupakan jalan utama untuk menuju ke Pascorner.

hasil kesimpulan competitor
benchmarking, Pascorner Cafe and Gallery mampu bersaing dalam industri bisnis cafe resto karena sudah memiliki kekuatan yang bisa bersaing dan memiliki konsep yang berbeda.

\section{3) Consumer Review}

Bukan hanya analisis kompetitor saja yang dilihat dari kacamata konsumen, menurut Watono \& Watono (2011), analisis konsumen juga perlu diperhatikan. Pasalnya pengetahuan terhadap nilai-nilai, cara berpikir dan perilaku konsumen harus diperhatikan agar terwujudnya strategi promosi yang baik bagi Pascorner Cafe and Gallery. Analisis yang dilakukan peneliti dalam analisis konsumen, ada dilingkup tiga lingkup, yakni Head Analisys, Heart Analisys, dan Hand Analisys. Head Analisys mengacu pada pengetahuan konsumen terhadap Pascorner, sedangkan Heart Analisys yang mengacu pada perasaan konsumen terhadap Pascorner.Hand Analisys mengacu pada perilaku konsumen yang akan dilakukan kepada Pascorner.

Head Analysis, dari proses yang diawali dari pemahaman hingga pengetahuan yang dimilki konsumen, akan membangun suatu keyakinan dan kepercayaan terhadap Pascorner Cafe and Gallery. Heart Analysis, di sisi lain, konsumen merasa puas dan memunculkan keyakinan yang memicu perasaan suka, loyal hingga pada akhirnya memiliki hubungan emosional dengan Pascorner Cafe and Gallery. 
Hand Analysis, dilihat dari pengetahuan yang dimiliki, dan dengan kepercayaan terhadap Pascorner Cafe and Gallery, maka konsumen akan membentuk perilaku yang berlanjut terhadap Pascorner

\section{4) Brand Review}

Menurut Watono \& Watono (2011), analisis lingkungan internal dilakukan untuk mengetahui kondisi dan mengetahui elemen-elemen penting yang nantinya akan dirancang atau ditambahkan pada saat perancangan strategi promosi. Tinjauan yang akan dilakukan antara lain portofolio merek. Ini berguna untuk mengetahui apa konsep dari Pascorner dan apakah perkembangan merek akan bagus nantinya. Selain itu, mengetahui segmentasi, target dan posisi dari Pascorner, mengetahui contact point yang pernah dilakukan oleh Pascorner serta mengetahui program komunikasi apa saja yang telah dilakukan selama ini untuk mendapatkan perhatian dari target audiens Pascorner. Peneliti menggunakan semua itu agar mengetahui lebih lanjut terkait lingkungan internal dari Pascorner, berikut adalah pembahasan dari analisis lingkungan internal:

Brand Portofolio Pascorner Cafe and Gallery merupakan cafe dengan desain santai, nyaman modern dan konsep perubahan untuk mantan narapidana. Kebersihan terjaga, fasilitas lengkap dan pelayanan yang baik ditetapkan. Cafe ini mengusung konsep "Sebuah karya mandiri kreasi EX-NAPI Indonesia, dari tangan para ahli memberikan sentuhan karya kuliner dengan bahan terbaik dan inovasi rasa berkelas dunia" untuk mencerminkan dirinya. Para pegawai Pascorner Cafe and Gallery tidak menggunakan pakaian formal, Hal tersebut dilakukan agar lebih fleksibel dan membuat cafe itu terlihat santai.

Dengan segmentasi wilayah Kota Bandung, rata-rata usia 15-55 tahun dengan SES BC, Pascorner memiliki target one product all segment karena Pascorner Cafe and Gallery melayani semua segmen. Pascorner juga memposisikan dirinya Konsumen dari berbagai kelas ekonomi yang datang berkunjung ke Pascorner Cafe and Gallery dengan berbagai tujuan, seperti mencari minum dan makan, mencari cafe yang nyaman, konsep yang unik, mencari hiburan hingga pengakuan sosial.

Program komunikasi pemasaran yang sudah dilakukan serta contact point dari kegatan itu disampaikan melalui advertising; brosur, placemat menu, standing banner, spanduk, media sosial Instagram lalu event serta sales promotion diskon dengan penggunaan membercard.

\section{b. Intent Circle}

Hasil analisis yang telah ditemukan akan dijabarkan kedalam bentuk tabel dan diperjelas dengan pembahasan mendalam tentang elemen-elemen yang terkandung didalamnya, sebagai berikut. 
Tabel 1 Intent Formulation

\begin{tabular}{|c|c|c|}
\hline $\begin{array}{l}\quad \text { Threat } \\
\text { Banyak cafe } \\
\text { dengan } \\
\text { produk sama } \\
\text { dan } \\
\text { Pengunjung } \\
\text { event musik } \\
\text { terjadi } \\
\text { kerusuhan }\end{array}$ & $\begin{array}{c}\text { Opportunity } \\
\text { Mantan } \\
\text { narapidana } \\
\text { butuh lahan } \\
\text { kerja }\end{array}$ & $\begin{array}{l}\quad \text { Problem } \\
\text { Berlatar } \\
\text { belakang } \\
\text { seorang } \\
\text { narapidana, } \\
\text { Karyawan } \\
\text { belum loyal, } \\
\text { kurangnya } \\
\text { promosi }\end{array}$ \\
\hline \begin{tabular}{l}
\multicolumn{1}{c}{ Weakness } \\
Promosi \\
lemah. Hanya \\
mengandalkan \\
tamu dan \\
karyawan, \\
karyawan \\
mantan \\
narapidana \& \\
lokasi masuk \\
ke dalam.
\end{tabular} & \begin{tabular}{l}
\multicolumn{1}{c}{ Strength } \\
Bekerja secara \\
kekeluargaan, \\
cafe nyaman, \\
cafe harga \\
bersahabat \& \\
event music
\end{tabular} & $\begin{array}{l}\text { Advantage } \\
\text { Mudah } \\
\text { bermasyarakat } \\
\text { \& pengalaman } \\
\text { bagi karyawan }\end{array}$ \\
\hline
\end{tabular}

\section{1) Solve-Leverage}

Menurut Watono \& Watono (2011), setelah seluruh isu dipetakan dalam masalah dan keuntungan, sekarang saatnya merumuskan penyelesaian masalah yang dihadapi oleh merek dan mendayagunakan keuntungankeuntungan yang didapatkan oleh merek. Hal ini didapatkan peneliti pada saat wawancara dengan informan utama yang menjelaskan bahwa masalah yang dihadapi Pascorner adalah karena mereka berlatar belakang seorang yang pernah hidup 'seperti itu', banyak karyawan yang sering 'keluar-masuk' cafe, tapi masalah itu dihadapinya dengan membicarakan jalan keluar yang mana sistem kerja di Pascorner itu adalah kekeluargaan. Selain itu, masalah yang dihadapinya adalah promosi yang masih lemah, tapi pascorner mensiasati dengan memperdayakan para tamu dan karyawannya yang selalu menyebarluaskan kepada kerabat bahwa mereka sedang berada di Pascorner. Adanya Pascorner memberikan banyak dampak positif bagi para karyawannya, mendayagunakan keuntungankeuntungan yang mereka dapatkan adalah suatu cara yang baik untuk mereka. Selain itu, mudahan dalam bermasyarakat adalah salah satu poin pertama, karena dengan adanya Pascorner ini. Karyawan yang merupakan mantan narapidana akan lebih mudah kembali lagi diterima bermasyarakat karena, mereka menunjukan kemauan untuk berubah kearah yang lebih baik. Selanjutnya, pengalaman yang bisa jadi belum pernah mereka dapatkan ketika mereka bekerja di cafe. Ini merupakan nilai lebih yang akan dapat mengubah mereka ke arah yang lebih baik.

\section{c. Strategy Circle}

Target audiens tidak perlu diubah karena sudah cocok dengan konsep allsegment. Brand soul yang ditunjukkan adalah cafe nyaman, ramah dikantong, menyenangkan, live music beda genre 
setiap minggu, mantan narapidana yang mau berubah. Selling idea yang muncul dari perumusan brand soul adalah "Hangout with The Positive Vibes"

Messages yang disampaikan dari selling idea adalah Ngadem (Ngaso dengan Musik), Nongkrong pake Dua Mata dan Minggu Bareng yang Beda. Contact point yang digunakan untuk menyampaikan messages tersebut melalui media daring dan konvensional seperti majalah, radio, Instagram, flyer, banner, brosur dan souvenir.

Marketing communication mix yang diterapkan agar promosi lebih maksimal dengan menggunakan berbagai saluran, yakni advertising media konvensional, membuat iklan di standing banner, flyer, brosur, koran kota/daerah dan majalah lifestyle. Selain itu, juga melalui event yang akan diiklankan di Radio dengan segmentasi yang sudah dituju serta media daring, Internet-ads melalui media sosial Instagram; e-poster dan \#Hashtag

Personal selling dilakukan dengan membuka stand pada saat diadakannya workshop UMKM atau social enterprise serta empromosikan Pascorner Cafe and Gallery pada saat ada event UMKM atau social enterprise.

Sales promotion dilakukan dengan membuat deals "Sweet Deals" yang merupakan tawaran menarik untuk mendapatkan promo lebih hematdengan membeli apapun dengan keterangan sebagai berikut; (1) Dua items yang berbeda hanya dengan harga Rp. 39.000,; (2) Tiga items yang berbeda hanya dengan harga Rp. 58.ooo,-; dan (3) Lima items yang berbeda hanya dengan harga Rp. 97.000,-
Diskon. Pascorner telah memiliki program membercard bagi para konsumen setianya. Program diskon baru ini, diskon diberikan kepada para konsumen yang memiliki membercard khususnya dengan membawa teman minimal tiga orang dan datang dengan warna pakaian yang seragam. Selain mendapatkan diskon khusus bagi pemilik membercard, konsumen ini akan mendapatkan poin yang nantinya akan bisa ditukarkan kepada menu makanan tertentu. Mendapatkan diskon khusus bagi followers Instagram @Pascorner17 dan upload foto di Pascorner dengan geo-tagging Pascorner Cafe and Gallery

Kontes, Pascorner Cafe and Gallery merupakan tempat yang unik pada dekorasi serta tata ruangnya. Kontes yang dilakukan adalah kontes fotografi dengan objek yang ada atau berkaitan langsung dengan cafe. Kontestan berlomba untuk mendapatkan jepretan yang unik dan menarik. Foto hasil jepretan para kontestan diminta untuk di post pada media sosial Instagram pribadi dengan tag foto ke akun media sosial Instagram Pascorner Cafe and Gallery serta menambahkan \#hashtag pada caption sebagai tanda untuk mengikuti kontes fotografi dari Pascorner Cafe and Gallery.

Trading Stamp. Dengan pembelian minimal Rp. 50.000,- dan berlaku kelipatan, konsumen akan mendapatkan satu stamp di kartu khusus yang diberikan oleh Pascorner Cafe and Gallery pada periode yang telah ditentukan. Jika stamp sudah memenuhi kolom, konsumen berhak mendapatkan hadiah menarik dari Pascorner Cafe and Gallery. 


\section{PENUTUP}

Dari hasil kajian ini, dapat disimpulkan sebagai berikut.

Pertama, Pascorner Cafe and Gallery merupakan sebuah UMKM social enterprise yang mana mereka 90\% karyawannya adalah mantan narapidana. Pengelompokan UMKM untuk Pascorner adalah di usaha mikro, karena omset perbulan dari Pascorner adalah Rp. 30.000.000 serta karyawan yang ada di Pascorner berjumlah kurang lebih 10 orang.

Kedua, dalam menjalankan strategi promosi, Pascorner Cafe and Galley telah melakukan tiga tools dari lima tools promotion mix (bauran promosi) dari Kotler \& Armstrong yakni, advertising (periklanan), sales promotion (promosi penjualan) serta public relations (hubungan masyarakat), sedangkan personal selling (penjualan perseorangan) dan direct marketing (penjualan langsung) belum dilakukannya. Adanya stigma negatif serta kurang maksimalnya promosi dari Pascorner membuat Pascorner kurang dikenal di masyarakat. Advertising yang dilakukan oleh Pascorner antara lain penyebaran brosur, pemasangan stand banner, pemasangan spanduk, pemakaian placemat menu dan iklan melalui media sosial Instagram, selanjutnya sales promotion. Sales promotion yang dilakukan oleh Pascorner adalah diskon dengan sistem membercard bagi konsumen yang telah mencapai mininum pembelanjaan yang telah ditentukan. Public relation atau hubungan masyarakat yang dilakukan Pascorner agar mempermudah menjalin hubungan baik dengan masyarakat adalah dengan cara membuat event musik dan komunitas, hal ini yang menjadi pembeda dari cafe-cafe lainnya karena di Pascorner tiap minggunya memiliki event yang bergilir sesuai jadwal serta demi menjaga hubungan baik dengan target audiens, Pascorner juga melakukan peliputan media melalui penggunaan komunikasi yang sesuai dengan karakter merek dan aliran event, biasanya event musik yang dilakukan peliputan oleh media streaming. Strategi promosi yang dilakukan Pascorner sudah baik, dan Pascorner pun sudah mampu bersaing, namun masih belum spesifik dilihat dari belum meratanya informasi yang didapatkan oleh khalayak atau target audiens karena, dalam melakukan komunikasi dengan khalayak dan target audiens harus diperhatikan karena hal tersebut sangat berperan dalam hal opini massa yang berkembang di masyarakat sehungga keberadaannya dapat menjadi pengaruh untuk Pascorner apabila tidak diperhatikan.

Ketiga, alternatif strategi promosi yang telah disusun merupakan hasil dari informasi informan serta konsep IMC Model Dwi Sapta dari Watono \& Watono, Pascorner memiliki kompetitor yang jaraknya berbeda 30om dari kompetitor tersebut, meskipun begitu para konsumen dari Pascorner lebih memilih Pascorner karena Pascorner memiliki konsep yang berbeda dengan kompetitornya tersebut, lalu konsumen yang telah memiliki pengetahuan dan pemahaman mengenai Pascorner setelah datang ke cafe, mereka mengatakan merasa puas dan memunculkan keyakinan yang memicu 
perasaan hubungan emosional, dan dari pengetahuan yang dimiliki serta kepercayaan terhadap Pascorner, konsumen akan membentuk perilaku yang berlanjut terhadap Pascorner. Latar belakang karyawan mantan narapidana tidak memberikan banyak sisi negatif untuk sekitar. Kekuatan yang dimiliki oleh Pascorner adalah bekerja secara kekeluargaan, cafe nyaman, harga makanan dan minuman yang ramah dikantong dan memiliki event yang berbeda ditiap minggunya. Kelemahan yang dimilikinya adalah promosi yang masih belum merata serta lokasi yang masuk ke dalam, bukan di jalan utama.

Keempat, target audiens yang menyasar kepada semua segmen, serta brand soul yang dimiliki oleh Pascorner adalah cafe nyaman, ramah dikantong, menyenangkan, event live musik beda genre disetiap minggunya dan yang paling membedakan adalah karyawan Pascorner adalah mantan narapidana yang mau berubah, hal ini dirumuskan kepada selling idea " Hangout with The Positive Vibes "yang akan disampaikan melalui berbagai contact point dari message serta marcom mix yang sudah dirancang mulai dari advertising yang menggunakan media konvensional seperti banner, flyer, brosur, koran serta radio, sedangkan media online lebih memaksimalkan fitur-fitur pada media sosial yang dimiliki Pascorner yaitu Instagram dengan Instagram-ads serta \#hashtag. Pada personal selling, Pascorner membuka stand untuk mempromosikan dirinya di acara-acara tentang UMKM atau social enterprise selanjutnya sales promotion yang ditawarkan berupa deals, diskon, kontes dan trading stamp yang masing-masing memiliki spesifikasi yang sudah disesuaikan dengan Pascorner. hubungan masyarakat atau public relations yang dimaksimalkan dengan cara mengadakan event tetapi Pascorner menjadi salah satu pihak sponsorship bagi event tersebut dan yang terakhir pada direct marketing, Pascorner bisa menggunakan SMS dan fitur media sosial yang dimiliki yaitu Instagram, dengan mengirimkan direct message yang berisi promo serta informasi dari Pascorner Cafe and Gallery.

Dari kesimpulan penelitian di atas, beberapa hal bisa direkomendasikan sebagai berikut. Pertama, perlunya memaksimalkan media sosial yang dimiliki oleh Pascorner yaitu Instagram, karena dua dari tiga informan mengetahui publikasi, promosi serta aktivitas yang akan diadakan Pascorner itu melalui Instagram. Media konvensional pun jangan dilupakan, karena banyak media konvensional yang masih mampu efektif untuk menarik perhatian khalayak. Kedua, perlunya mengikuti acara yang mengenai UMKM yang diadakan oleh berbagai pihak (pemerintah atau swasta) agar meningkatkan pengetahuan dan kesadaran masyarakat terkait produk UMKM yang berkualitas serta berguna bagi Pascorner untuk belajar dengan sesama. Ketiga, perlunya bekerja sama dengan komunitas atau bergabung dengan asosiasi social enterprise atau pun asosiasi UMKM untuk mendapatkan ilmu yang lebih banyak khususnya untuk memaksimalkan ketenaga kerjaan yang dimiliki oleh Pascorner serta mendapat dukungan lebih dari pemerintah atau swasta untuk menyelesaikan keterbatasan yang Pascorner miliki. 


\section{DAFTAR PUSTAKA}

Kotler, P., \& G Amstrong. (2008). Principles Of Marketing, 12th Edition, New Jersey: Pearson Education Inc/Prentice Hall.

Kushnir, Khrystyna., , Melina Laura Mirmulstein, and Rita Ramalho. (2010). Micro, Small, and Medium Enterprises Around the World: How Many Are There, and What Affects the Count?. MSME Country Indicators. World Bank / IFC

Moleong, Lexy. (2007). Metode Penelitian Kualitatif. Bandung: PT. Remaja Rosdakarya.

Watono, A. Adji \& Maya C Watono. (2011). Integrated Marketing Communication that Sells. Jakarta: PT. Gramedia
Wibhawa, Budhi., dkk. (2011). Social Entrepreneurship, Social Enterprise, \& Corporate Social Responsibility. Bandung: Widya Padjajaran

Yin, Robert K. (2008). Studi Kasus Desain dan metode, Raja Grafindo Persada. Jakarta

\section{Internet:}

http://www.investopedia.com/terms/s/so cial-enterprise.asp (18 oktober 2017, pukul 22:48) 